\title{
Knowledge, attitude and practice of preventing spread of COVID-19 amongst orthopaedic surgeons and residents in a tertiary care hospital in Navi-Mumbai
}

\author{
Prakash D. Samant, Rohit M. Sane*
}

Department of Orthopaedics, D. Y. Patil University School of Medicine, Navi-Mumbai, Maharashtra, India

Received: 27 July 2020

Accepted: 11 September 2020

\author{
*Correspondence: \\ Dr. Rohit M. Sane, \\ E-mail: dr.sanerohit@gmail.com
}

Copyright: ( $)$ the author(s), publisher and licensee Medip Academy. This is an open-access article distributed under the terms of the Creative Commons Attribution Non-Commercial License, which permits unrestricted non-commercial use, distribution, and reproduction in any medium, provided the original work is properly cited.

\begin{abstract}
Background: With on-going coronavirus pandemic, there is high incidence of COVID-19 occupational risk exposure among health care professionals. The aim of this study was to assess the knowledge, attitude and practice (KAP) amongst orthopaedic surgeons and residents regarding prevention of spread of COVID-19 at a tertiary care hospital.

Methods: A cross-sectional, observational, web-based questionnaire study was conducted at orthopaedic department of a tertiary care hospital in Navi Mumbai. The study included orthopaedic surgeons and residents of either sex. A predesigned KAP questionnaire was used to assess the knowledge, attitude and practice regarding prevention of spread of COVID-19. The web-based questionnaire was circulated to eligible participants and the responses obtained were analysed.

Results: Overall, the knowledge regarding hand hygiene, mask etiquette and COVID-19 diagnoses was high. Majority participants knew the proper technique of personal protective equipment (PPE), but few $25 \%$ and $35 \%$ lacked correct technique for donning and doffing of PPE respectively. Majority participants knew the indications and pre/postoperative protocols for orthopaedic surgeries in COVID-19. Around 40\% only knew the type of pressure system used in the COVID-19 operation theatre (OT). Majority felt that mask, hand hygiene and PPE were essential kit for prevention. In practice, majority participants were taking drug prophylaxis and were adequately practicing mask/hand hygiene.

Conclusions: Overall, KAP regarding prevention of spread of COVID-19 among orthopaedicians were adequate. Further formal preventive education on COVID-19 and structured hands-on experience workshops are necessary to advance the proper techniques of PPE handling.
\end{abstract}

Keywords: KAP, COVID-19, Orthopaedics, Prevention

\section{INTRODUCTION}

The World Health Organisation (WHO) declared global pandemic of coronavirus disease 2019 (COVID-19) caused by SARS - CoV-2 virus was first reported from China in December 2019 and is now engulfing the entire globe including India. ${ }^{1}$ India witnessed the first report in January 2020 from Kerala and since then thousands of cases have been reported from all the states, with Maharashtra being the country's most affected state. ${ }^{2-4}$
The COVID-19 pandemic created a big dilemma especially in health care workers (HCWs) who were involved in managing patients with this highly transmittable pathogen with limited resources. ${ }^{5}$ COVID19 posed a significant health risks to the HCWs due to their frequent close contact with highly infectious patients. ${ }^{5-7}$

Studies have documented a high incidence of COVID-19 exposure and mortality rates among health care professionals in the line of their duty, raising serious 
concerns about the adequacy of the preventive strategies adopted, including hand hygiene and personal protective equipment among health care professionals. ${ }^{8-10}$

Knowledge, attitudes and practice (KAP) surveys are an important way to evaluate the adopted current initiatives and for identifying the gaps and implementing effective strategies. There are very limited studies that document KAPs among health care professionals regarding COVID19. The present study was aimed to assess the KAP amongst orthopaedic surgeons and residents regarding prevention of spread of COVID-19 at a tertiary care hospital in Navi Mumbai (Maharashtra).

\section{METHODS}

A cross-sectional, observational, web-based questionnaire study was conducted at orthopaedic department of a tertiary care hospital in Navi Mumbai. Ethical clearance was obtained from the Institutional Ethics Committee.

The study duration was one month and was conducted in the month of June 2020. The sampling method was convenient sample.

The study included orthopaedic surgeons and residents of either sex. A predesigned KAP questionnaire was used to assess KAP regarding prevention of spread of COVID-19. The KAP questionnaire had questions assessing the knowledge, attitude and practice domains with multiple choices/“yes" or "no" options to answer. The knowledge questions were scored for analysis. Each correct answer was given one point, and an incorrect answer was given zero.

A web-based KAP questionnaire was created in Google forms with incorporation of informed consent at the beginning of the survey. The web link of the KAP survey was circulated to the eligible participants via Whatsapp and email. Participants who gave online consent were allowed to access the survey questionnaire further and participate in the web-based survey. The responses obtained were analysed for KAP aspects. The maximum score obtainable for knowledge was 14. An overall score of 14 was considered excellent, 11-3 was considered good, 7-10 moderate, and less than 7 was taken as poor.

Data was analysed on the Statistical Package for the Social Sciences (SPSS) version 20. Descriptive statistics were presented using means and standard deviation for continuous variables, frequencies, and percentages for categorical variables. T-test was used to compare the knowledge score between the groups. $\mathrm{P}<0.05$ was considered as statistically significant.

\section{RESULTS}

A total of forty eight participants took part in this KAP survey. The survey response rate of this KAP survey was $100 \%$.

\section{Knowledge}

Overall, the knowledge regarding hand hygiene, mask etiquette and COVID-19 diagnosis was high. The mean knowledge score of the sample was $12.1 \pm 1.8$. Majority participants had "good-excellent" level of knowledge (Figure 1). The mean knowledge score was higher in orthopaedic surgeon $(12.56 \pm 1.75)$ than resident (11.87 \pm 1.8$)$ but the difference was not significant (Table 1). Majority participants knew the proper technique of personal protective equipment (PPE), but few $25 \%$ and $35 \%$ lacked correct technique for donning and doffing of PPE respectively. Majority participants knew the indications and pre/post-operative protocols for orthopaedic surgeries in COVID-19. Around $40 \%$ only knew the type of pressure system used in the COVID-19 operation theatre (OT) (Table 2).

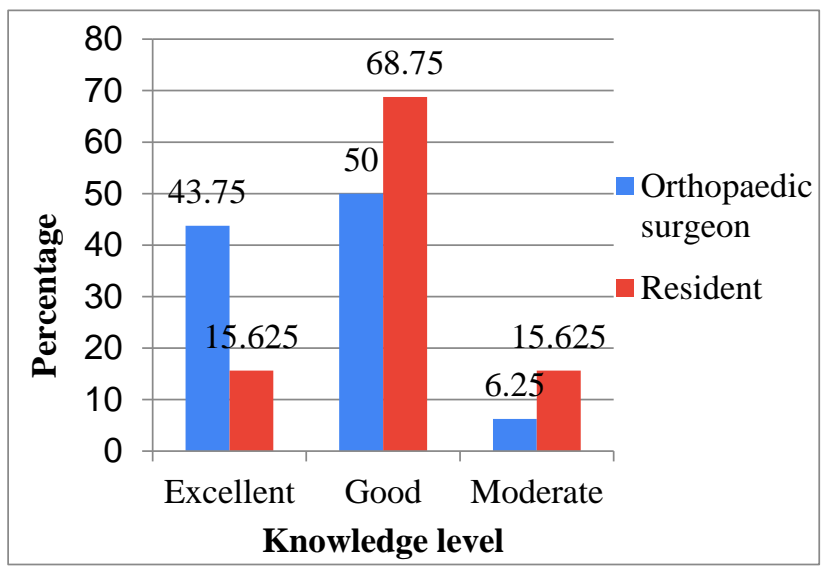

Figure 1: Level of knowledge.

Table 1: Showing age distribution of patients.

\begin{tabular}{|c|c|c|c|c|c|}
\hline Group & & $\mathbf{N}$ & Mean & $\begin{array}{l}\text { T- } \\
\text { value }\end{array}$ & $\begin{array}{l}P \\
\text { value }\end{array}$ \\
\hline \multirow{2}{*}{$\begin{array}{l}\text { Know } \\
\text {-ledge } \\
\text { score }\end{array}$} & Resident & 32 & $\begin{array}{l}11.87 \\
\pm 1.8\end{array}$ & \multirow{2}{*}{-1.25} & \multirow{2}{*}{0.216} \\
\hline & $\begin{array}{l}\text { Orthopaedic } \\
\text { surgeon }\end{array}$ & 16 & $\begin{array}{l}12.56 \\
\pm 1.75\end{array}$ & & \\
\hline
\end{tabular}

\section{Attitude}

Majority $(93.8 \%)$ felt that mask and hand hygiene were essential for COVID-19 prevention. Majority (85.4\%) thought that alcohol-based sanitizers were not superior to soap and water hand wash, if the hands were visible dirty and soiled. Majority felt that COVID-19 pandemic had a permanent impact on people's lives and affected the choice of management pertaining to specific illness (Figure 2).

\section{Practice}

In practice, majority participants were taking drug prophylaxis for COVID-19 prevention and were adequately practicing mask/hand hygiene regularly in dayto-day practice (Figure 3). 
Table 2: Knowledge-related questions.

\begin{tabular}{|c|c|c|}
\hline Knowledge questionnaire & $\begin{array}{l}\text { Correct } \\
\text { response (\%) }\end{array}$ & $\begin{array}{l}\text { Uncorrect } \\
\text { response }(\%)\end{array}$ \\
\hline Who is considered as a COVID-19 suspected case? & 97.92 & 2.08 \\
\hline Who is considered as a COVID-19 confirmed case? & 93.75 & 6.25 \\
\hline What are the clinical features of a COVID-19? & 100 & 0 \\
\hline How to confirm a COVID-19 case? & 93.75 & 6.25 \\
\hline Which are the risk group categories? & 100 & 0 \\
\hline From where the specimen sample for COVID-19 is taken? & 100 & 0 \\
\hline What is COVID-19 hand hygiene? & 100 & 0 \\
\hline What is COVID-19 mask etiquette? & 93.75 & 6.25 \\
\hline What are the correct steps of donning PPE? & 75 & 25 \\
\hline What are the correct steps of doffing PPE? & 64.58 & 35.42 \\
\hline What are the drugs and doses used for prophylaxis in healthcare workers? & 87.50 & 16.67 \\
\hline What are the indications for orthopaedic surgeries in times of COVID-19? & 85.42 & 14.58 \\
\hline Are you aware of the intra and postoperative protocols for COVID-19? & 66.67 & 33.33 \\
\hline $\begin{array}{l}\text { What type of pressure system is used in the COVID-19 operation theater } \\
\text { (OT)? }\end{array}$ & 41.67 & 58.33 \\
\hline
\end{tabular}

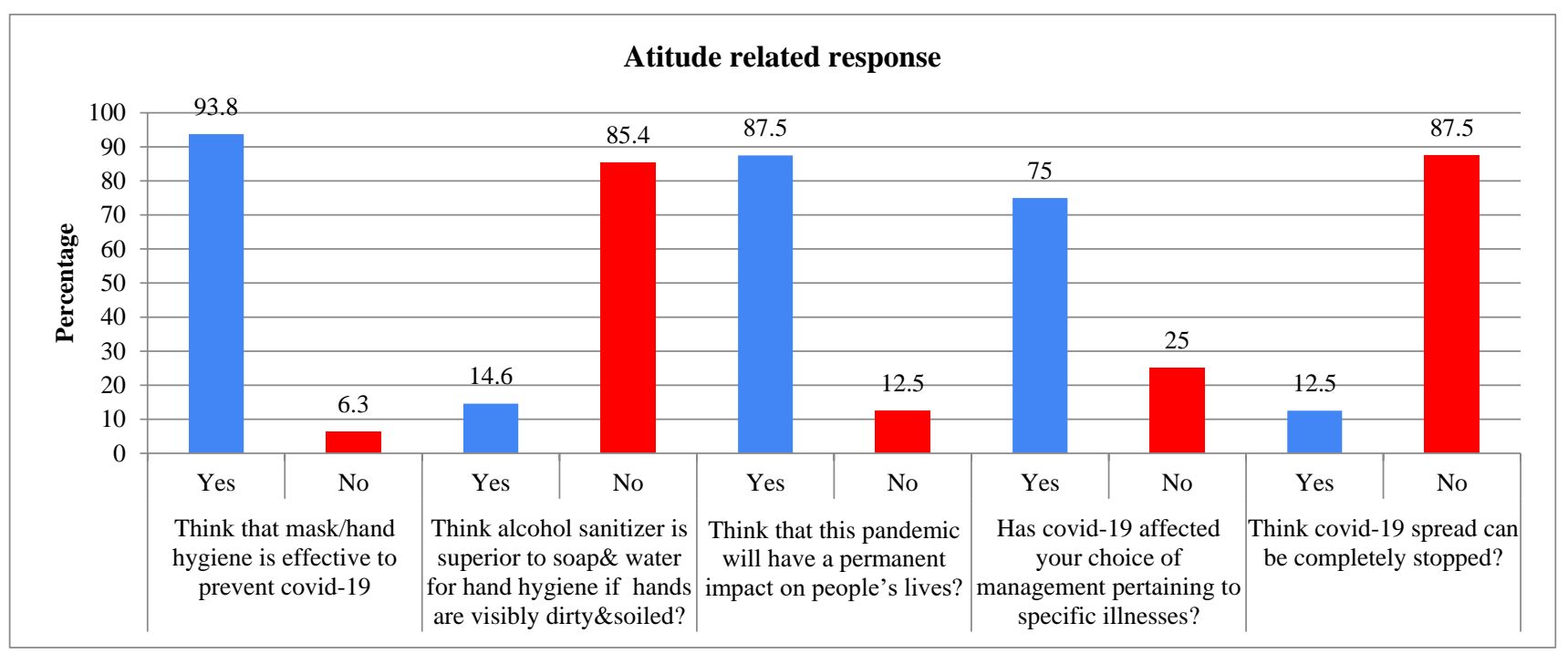

Figure 2: Attitude-related responses.

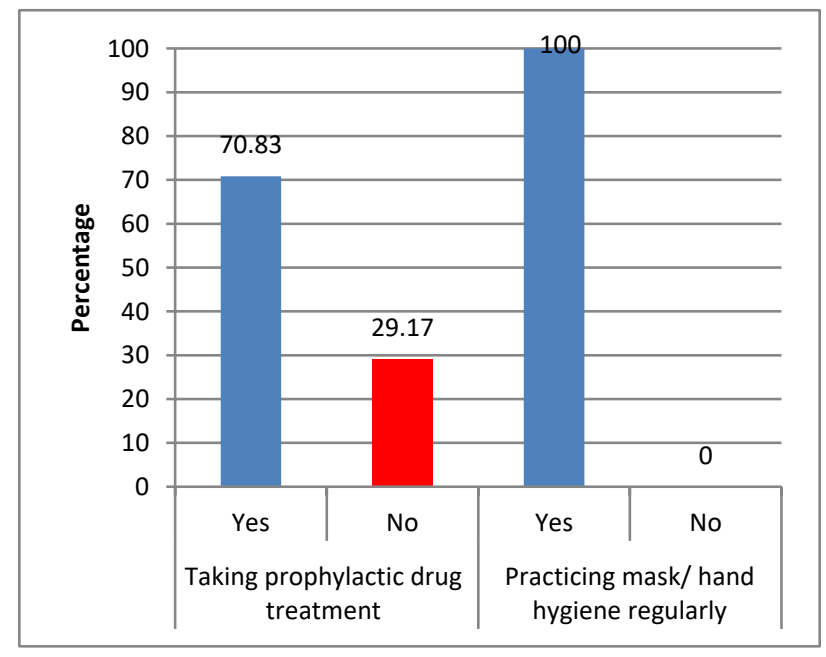

Figure 3: Practice of preventing COVID-19.

\section{DISCUSSION}

COVID-19 has emerged as the worst pandemic disease of this century, debilitating the health of general population and the frontline health care professionals. It is utmost importance that frontline treating health care professionals have adequate knowledge, positive attitude and are abreast with all aspects of the COVID-19 disease from clinical features, diagnosis, treatment, and established prevention strategies in this health crisis.

This is the first KAP study regarding COVID-19 done among orthopaedic surgeons from India to the best of our knowledge. There are very limited studies that document KAPs among health care professionals.

In this study, the mean knowledge score among the orthopaedicians was high and majority $(>90 \%)$ had "good 
to excellent" level of knowledge regarding COVID-19. These findings of sufficient knowledge are similar to studies conducted by Saqlain et al, Zhang et al, Nepal et al, Taneja et al, Modi et al, and Olum et al in which majority of the participants had good knowledge. ${ }^{7,11-15}$ Due to differences in KAP questionnaire and scoring in literature studies, we were not able to accurately compare the knowledge scores with previous studies.

In this study, the mean knowledge score was higher in orthopaedic surgeon $(12.56 \pm 1.75)$ than resident $(11.87 \pm 1.8)$ but the difference was not significant. Our study finding support the findings of Olum et al in which the knowledge among the healthcare workers were similar irrespective of the cadre/academic qualification. ${ }^{15}$ However, studies have documented qualification and years of experience play a role in the knowledge aspect. ${ }^{13,14}$

In this study, majority participants knew the proper technique of PPE, but few $25 \%$ and $35 \%$ lacked correct technique for donning and doffing of PPE respectively. It is important to know the correct sequence of "donning and doffing" of PPE in handling suspected/confirmed COVID19 case as it is necessary to prevent further contamination and infection. From the perspective of prevention and control, HCWs should place a high value on correct removal of protective equipment. Several agencies have emphasised on the correct usage of PPE for optimal benefit. $^{16-20}$

In this study, majority participants knew the orthopaedic indications and the intra and postoperative protocols for COVID-19. However few knew regarding the type of pressure system used in the COVID-19 operation theater setting. It is esential to have adequate knowledge regarding the standard operating procedures and firmly adhere to the peri-operative protocols for optimal infection prevention and control in the orthopaedic setting.

Overall in this study, the knowledge regarding hand hygiene, mask etiquette, PPE and COVID-19 diagnoses were high. The possible explanation for this high knowledge could be that it was conducted in the middle phase of the crisis when protocols and guideline were released and also may be due to the fact that majority had undergone training in the initial phase of the crisis.

In this study, majority participants $(93.8 \%)$ felt that mask and hand hygiene were essential for COVID-19 prevention. Majority (85.4\%) thought that alcohol-based sanitizers were not superior to soap and water hand wash, if the hands were visible dirty and soiled which is in accordance to WHO recommendations for hand hygiene. ${ }^{21}$

Overall the attitude in this study was positive and promising in this study. Previous studies have associated high levels of knowledge with high confidence and positive attitudes in health crises. ${ }^{7,11,12}$ However, majority felt and believed that COVID-19 pandemic will have a permanent impact on people's lives and will affect the choice of management pertaining to specific illness.

HCWs endure considerable mental and physical stress caring for patients with COVID-19. ${ }^{22,23}$ It is therefore imperative to know and address the immediate needs of these caregivers by identifying the gap and addressing the issues promptly in this health crisis.

In this study, majority participants reported good practices. Majority participants were taking drug prophylaxis for COVID-19 prevention and were adequately practicing mask/hand hygiene regularly in day-to-day practice. These are very vital to improvise surgical practice to the best of their ability to prevent transfer of COVID-19 from patients to patients and to the HCWs themselves.

Further enhancement of practices with a background of a good level of knowledge can be conducted by streamlining standard operating procedures/guidelines, and workshop based first-hand experience on PPE kit techniques and trainings on preventive strategies.

The limitations of this study were that it was conducted at a single orthopaedic department and the survey was based on a self-reported questionnaire, which may be susceptible to subjective bias.

\section{CONCLUSION}

In this study, majority participants reported good practices. These are very vital to improvise surgical practice to the best of their ability to prevent transfer of COVID-19 from patients to patients and to the HCWs themselves. Further enhancement of practices with a background of a good level of knowledge can be conducted by streamlining standard operating procedures/guidelines, and workshop based first-hand experience on PPE kit techniques and trainings on preventive strategies.

\section{ACKNOWLEDGEMENTS}

The authors would like to acknowledge the support and cooperation of residents and staff orthopaedic surgeons for their participation in this survey.

Funding: No funding sources

Conflict of interest: None declared

Ethical approval: The study was approved by the institutional ethics committee

\section{REFERENCES}

1. World Health Organization (WHO). Coronavirus Disease 2019 (COVID-19) Situation Report - 98. Available at: https://www.who.int/docs/defaultsource/coronaviruse/situation-reports/20200427-sitr ep-98-covid-19.pdf?sfvrsn=90323472_4. Accessed on 20 June 2020. 
2. Ministry of Health and Family Welfare. COVID 19India. Available at: https://www.mohfw.gov.in/. Accessed on 20 June 2020.

3. Koul PA, Dhar R. COVID-19 pandemic in India: A clarion call for better preparedness. Lung India. 2020;37:187-9.

4. World Health Organization (WHO). Coronavirus Disease 2019 (COVID-19) -India Situation Report. Available at: https://www.who.int/india/emergen cies/coronavirus-disease-(covid-19)/india-situationreport. Accessed on 20 June 2020.

5. Singh H, Sharma S. Concerns of Frontline Doctors in India during COVID-19: A Cross-Sectional Survey. Indian J Public Health. 2020;64:237-9.

6. Hoe Gan W, Wah Lim J, Koh D. Preventing intrahospital infection and transmission of COVID-19 in healthcare workers. Version 2. Saf Health Work. 2020;11(2):241-3.

7. Saqlain M, Munir MM, Rehman SU, Gulzar A, Naz S, Ahmed Z, et al. Knowledge, attitude, practice and perceived barriers among healthcare professionals regarding COVID-19: A Cross-sectional survey from Pakistan. J Hosp Infect. 2020;105(3):419-23.

8. Chen Y, Tong X, Wang J, Huang W, Yin S, Huang $\mathrm{R}$, et al. High SARS-CoV-2 antibody prevalence among healthcare workers exposed to COVID-19 patients. J Infect. 2020;81(3):420-6.

9. Jha S, Soni A, Siddiqui S, Batra N, Goel N, Dey S, Budhiraja S, Naithani R. Prevalence of Flu-like Symptoms and COVID-19 in Healthcare Workers from India. J Assoc Physicians India. 2020;68(7):279.

10. Ing EB, Xu QA, Salimi A, Torun N. Physician deaths from corona virus (COVID-19) disease. Occup Med (Lond). 2020:70(5):370-4.

11. Zhang M, Zhou M, Tang F, Wang Y, Nie H, Zhang L, You G. Knowledge, attitude, and practice regarding COVID-19 among healthcare workers in Henan, China. J Hosp Infect. 2020;105(2):183-7.

12. Nepal R, Sapkota K, Adhikari K, Paudel P, Adhikari B, Paudyal N. Knowledge, attitude and practice regarding COVID-19 among healthcare workers in Chitwan, Nepal. Research square journal. 2020.

13. Taneja D, Khurana A. An online cross-sectional survey on knowledge, attitudes, practices and perspectives of homoeopathic practitioners towards COVID-19. Indian J Res Homoeopathy. 2020;14:909.

14. Modi PD, Nair G, Uppe A, Modi J, Tuppekar B, Gharpure AS, et al. COVID-19 Awareness Among Healthcare Students and Professionals in Mumbai Metropolitan Region: A Questionnaire-Based Survey. Cureus. 2020;12(4):7514.

15. Olum R, Chekwech G, Wekha G, Nassozi DR, Bongomin F. Coronavirus Disease-2019:
Knowledge, Attitude, and Practices of Health Care Workers at Makerere University Teaching Hospitals, Uganda. Front Public Health. 2020;8:181.

16. Ministry of Health and Family Welfare, Government of India. Novel Coronavirus Disease 2019 (COVID19): Guidelines on rational use of Personal Protective Equipment. Available at: https://www.mohfw.gov.in /pdf/GuidelinesonrationaluseofPersonalProtectiveEq uipment.pdf. Accessed on 20 July 2020.

17. Ministry of Health and Family Welfare, Government of India. National guidelines for infection prevention and control in healthcare facilities. Available at: https://www.mohfw.gov.in/pdf/National\%20Guideli nes $\% 20$ for $\% 20$ IPC $\% 20$ in $\% 20 \mathrm{HCF} \% 20$ $\% 20$ final\%281\%29.pdf. Accessed on 20 July 2020.

18. All India Institute Of Medical Sciences (AIIMS, New Delhi) Covid Portal. Donning and Doffing the Personal Protective Equipment. Available at: https://covid.aiims.edu/personal-protective-equipme nt-covid-19-preparedness/. Accessed on 20 July 2020.

19. Centers for Disease Control and Prevention (CDC). Coronavirus Disease 2019 (COVID-19). Using Personal Protective Equipment (PPE). Available at: https://www.cdc.gov/coronavirus/2019-ncov/hcp/usi ng-ppe.html. Accessed on 20 July 2020.

20. World Health Organization (WHO). How to put on and take off Personal Protective Equipment (PPE). Available at: https://www.who.int/csr/resources/ publications/putontakeoffPPE/en/. Accessed on 20 July 2020.

21. World Health Organisation. WHO Guidelines on HandHygiene in Health Care: First Global Patient Safety Challenge Clean Care Is Safer Care. Geneva: World Health Organization Press; 2009. Available at: https://www.who.int/gpsc/5may/tools/97892415979 06/en/. Accessed on 20 July 2020.

22. Chatterjee SS, Bhattacharyya R, Bhattacharyya S, Gupta S, Das S, Banerjee BB. Attitude, practice, behavior, and mental health impact of COVID-19 on doctors. Indian J Psychiatry. 2020;62:257-65.

23. Balasubramanian A, Paleri V, Bennett R, Paleri V. Impact of COVID-19 on the mental health of surgeons and coping strategies. Head Neck. 2020;42(7):1638-44.

Cite this article as: Samant PD, Sane RM.

Knowledge, attitude and practice of preventing spread of COVID-19 amongst orthopaedic surgeons and residents in a tertiary care hospital in NaviMumbai. Int J Res Orthop 2020;6:1228-32. 